\title{
Roles of $\mathrm{Cu}$ in the Enhanced Thermoelectric Properties in $\mathrm{Bi}_{0.5} \mathrm{Sb}_{1.5} \mathrm{Te}_{3}$
}

\author{
Feng Hao ${ }^{1,2}$, Pengfei Qiu ${ }^{1, *}$, Qingfeng Song ${ }^{1,2}$, Hongyi Chen ${ }^{1}$, Ping Lu ${ }^{1}$, Dudi Ren ${ }^{1}$, Xun Shi ${ }^{1}$ \\ and Lidong Chen ${ }^{1, *}$ \\ 1 State Key Laboratory of High Performance Ceramics and Superfine Microstructure, \\ Shanghai Institute of Ceramics, Chinese Academy of Sciences, Shanghai 200050, China; \\ haofeng@student.sic.ac.cn (F.H.); songqingfeng@student.sic.ac.cn (Q.S.); \\ chenhy@shanghaitech.edu.cn (H.C.); pinglu@mail.sic.ac.cn (P.L.); \\ rendudi@mail.sic.ac.cn (D.R.); xshi@mail.sic.ac.cn (X.S.) \\ 2 University of Chinese Academy of Sciences, 19 Yuquan Road, Beijing 100049, China \\ * Correspondence: qiupf@mail.sic.ac.cn (P.Q.); cld@mail.sic.ac.cn (L.C.); \\ Tel.: +86-21-5241-2522 (P.Q.); +86-21-5241-4804 (L.C.)
}

Academic Editor: Paz Vaqueiro

Received: 19 January 2017; Accepted: 24 February 2017; Published: 1 March 2017

\begin{abstract}
Recently, $\mathrm{Cu}$-containing p-type $\mathrm{Bi}_{0.5} \mathrm{Sb}_{1.5} \mathrm{Te}_{3}$ materials have shown high thermoelectric performances and promising prospects for practical application in low-grade waste heat recovery. However, the position of $\mathrm{Cu}$ in $\mathrm{Bi}_{0.5} \mathrm{Sb}_{1.5} \mathrm{Te}_{3}$ is controversial, and the roles of $\mathrm{Cu}$ in the enhancement of thermoelectric performance are still not clear. In this study, via defects analysis and stability test, the possibility of $\mathrm{Cu}$ intercalation in p-type $\mathrm{Bi}_{0.5} \mathrm{Sb}_{1.5} \mathrm{Te}_{3}$ materials has been excluded, and the position of $\mathrm{Cu}$ is identified as doping at the $\mathrm{Sb}$ sites. Additionally, the effects of $\mathrm{Cu}$ dopants on the electrical and thermal transport properties have been systematically investigated. Besides introducing additional holes, $\mathrm{Cu}$ dopants can also significantly enhance the carrier mobility by decreasing the Debye screen length and weakening the interaction between carriers and phonons. Meanwhile, the $\mathrm{Cu}$ dopants interrupt the periodicity of lattice vibration and bring stronger anharmonicity, leading to extremely low lattice thermal conductivity. Combining the suppression on the intrinsic excitation, a high thermoelectric performance-with a maximum thermoelectric figure of merit of around 1.4 at $430 \mathrm{~K}$-has been achieved in $\mathrm{Cu}_{0.005} \mathrm{Bi}_{0.5} \mathrm{Sb}_{1.495} \mathrm{Te}_{3}$, which is $70 \%$ higher than the $\mathrm{Bi}_{0.5} \mathrm{Sb}_{1.5} \mathrm{Te}_{3}$ matrix.
\end{abstract}

Keywords: bismuth telluride; thermoelectric; defect; microstructures

\section{Introduction}

Utilizing energy in high-efficiency and ecofriendly ways is an urgent task in modern society. However, due to the low efficiency of traditional energy conversion technologies, more than $60 \%$ of the total energy is dissipated as waste heat, with the temperatures ranging from ambient temperature to over $1000{ }^{\circ} \mathrm{C}$ [1]. Thermoelectric (TE) materials can realize a direct conversion between heat and electricity with the characters of high reliability and zero pollution, and thus provide an alternative choice to use the energy more efficiently [2]. The energy conversion efficiency of a TE material is governed by the figure of merit $z T=S^{2} \sigma T / \kappa$, where $S$ is the Seebeck coefficient, $\sigma$ is the electrical conductivity, $T$ is the absolute temperature, and $\kappa$ is the thermal conductivity [3]. In order to maximize energy conversion efficiency, a large $S$, a high $\sigma$, and a low $\kappa$ are required to obtain a high $z T$.

Currently, the best commercial p-type TE materials near room temperature are $\mathrm{Bi}_{2} \mathrm{Te}_{3}-\mathrm{Sb}_{2} \mathrm{Te}_{3}$-based alloys developed in the 1950s [4]. Lots of lattice defects are observed in $\mathrm{Bi}_{2} \mathrm{Te}_{3}-\mathrm{Sb}_{2} \mathrm{Te}_{3}$-based alloys due to the presence of $\mathrm{Bi} / \mathrm{Sb}$ atomic disorder distributions and $\mathrm{Sb} / \mathrm{Te}$ antisites. These point defects can strongly scatter high-frequency heat-carrying phonons to lower 
lattice thermal conductivities and consequently lead to excellent TE performances. However, the peak $z T$ s of these alloys usually appear around room temperature because of their small band gaps (less than $0.2 \mathrm{eV}$ ) [5]. At high temperature, the $z T \mathrm{~s}$ are severely degraded due to the enhanced $k$ and quickly decreased $S$ caused by the thermal-activated bipolar effect $[6,7]$. Thus, the applications of these materials for harvesting waste heat as TE power generators are greatly limited. Some effective strategies have been adopted to suppress this thermal-activated bipolar effect. Among them, introducing a tiny amount of $\mathrm{Cu}$ into p-type $\mathrm{Bi}_{2} \mathrm{Te}_{3}-\mathrm{Sb}_{2} \mathrm{Te}_{3}$-based alloys can effectively decrease the minor carrier (electron) density and significantly weaken the negative effects of minor carriers on the TE performance [8]. High zTs, about 1.4 at 400-500 K, have been successfully obtained in $\mathrm{Cu}_{0.005} \mathrm{Bi}_{0.5} \mathrm{Sb}_{1.495} \mathrm{Te}_{3}$. Furthermore, the TE modules based on the developed $\mathrm{Cu}_{0.005} \mathrm{Bi}_{0.5} \mathrm{Sb}_{1.495} \mathrm{Te}_{3}$ material show a high energy conversion efficiency, about $6 \%$ under a temperature gradient of $217 \mathrm{~K}$, superior to the modules using undoped materials.

In spite of the much enhanced TE performance, the roles of $\mathrm{Cu}$ in the electrical and thermal transports in p-type $\mathrm{Bi}_{2} \mathrm{Te}_{3}-\mathrm{Sb}_{2} \mathrm{Te}_{3}$-based alloys are still not completely clarified. Especially, the occupancy site of $\mathrm{Cu}$ atoms is a matter of ongoing debate. Currently, there are two different standpoints. One is that the $\mathrm{Cu}$ atoms are in the van der Waals gaps between the two adjacent $\mathrm{Te}$ layers in the crystal structure as intercalated ions to introduce excess electrons to the system. As early as 1970, McCarthy et al. [9] found that the external electric field could drive $\mathrm{Cu}$ ions into the van der Waals gap. In 2011, Liu et al. [10] proposed the presence of $\mathrm{Cu}$ ions in the van der Waals gap of $\mathrm{Bi}_{2} \mathrm{Te}_{2.7} \mathrm{Se}_{0.3}$ via the characterization and analysis of electrical transport properties and lattice parameters. In 2014, theoretical calculations showed that the formation energy of $\mathrm{Cu}$ intercalation in p-type $\mathrm{Bi}_{2} \mathrm{Te}_{3}$ is favorable [11]. Another point is that the $\mathrm{Cu}$ atoms prefer to enter the $\mathrm{Sb}$ sites due to the small electronegativity and radius difference between $\mathrm{Cu}$ and $\mathrm{Sb}[12,13]$. Considering that the valence state of $\mathrm{Cu}$ ions is +2 , its substitution in the $\mathrm{Sb}^{3+}$ site is expected to introduce additional holes to the system, which is completely contrary to the first standpoint. Nevertheless, the substitution of $\mathrm{Cu}$ in the $\mathrm{Sb}$ sites is well supported by the enhanced $\sigma$ and lowered $S$ values obtained in experiments.

In this work, we carried out a further study on the occupancy sites of $\mathrm{Cu}$ atoms in p-type $\mathrm{Bi}_{0.5} \mathrm{Sb}_{1.5} \mathrm{Te}_{3}$ materials. Investigations on the phase compositions, microstructures, electrical and thermal transports, and material stabilities show that the $\mathrm{Cu}$ atoms are doped at the $\mathrm{Sb}$ sites rather than entering the van der Waals gap in $\mathrm{Bi}_{0.5} \mathrm{Sb}_{1.5} \mathrm{Te}_{3}$. Then, the roles of $\mathrm{Cu}$ atoms on the TE properties were systematically analyzed.

\section{Results and Discussion}

Figure 1a,c shows the powder XRD patterns for nominal $\mathrm{Cu}$-doped $\mathrm{Cu}_{x} \mathrm{Bi}_{0.5} \mathrm{Sb}_{1.5-x} \mathrm{Te}_{3}$ and nominal $\mathrm{Cu}$-intercalating $\mathrm{Cu}_{x} \mathrm{Bi}_{0.5} \mathrm{Sb}_{1.5} \mathrm{Te}_{3}$ samples. All the peaks are indexed with the standard $\mathrm{Bi}_{0.5} \mathrm{Sb}_{1.5} \mathrm{Te}_{3}$ phase (PDF\#49-1713). No obvious impurity phase is detected. We further refined the lattice parameters of these $\mathrm{Bi}_{2} \mathrm{Te}_{3}-\mathrm{Sb}_{2} \mathrm{Te}_{3}$-based alloys by using the Rietveld method. The results are shown in Figure $1 \mathrm{~b}, \mathrm{~d}$, respectively. If the $\mathrm{Cu}$ atoms go into the van der Waals gaps as intercalated ions, the lattice parameter $a$ should be scarcely changed, but lattice parameter $c$ should be greatly increased [10]. In contrast, if the $\mathrm{Cu}$ atoms occupy the $\mathrm{Sb}$ sites, both $a$ and $c$ should be decreased because the atomic radius of $\mathrm{Cu}(135 \mathrm{pm})$ is smaller than that of $\mathrm{Sb}$ atoms (145 pm). As shown in Figure $1 \mathrm{~b}$, the monotonous reduction in $a$ and $c$ with increasing $\mathrm{Cu}$ content strongly suggests that $\mathrm{Cu}$ atoms enter the $\mathrm{Sb}$ sites in the $\mathrm{Cu}_{x} \mathrm{Bi}_{0.5} \mathrm{Sb}_{1.5-x} \mathrm{Te}_{3}$ samples. Similar lattice contractions are also observed in nominal $\mathrm{Cu}$-intercalating $\mathrm{Cu}_{x} \mathrm{Bi}_{0.5} \mathrm{Sb}_{1.5} \mathrm{Te}_{3}$ samples (see Figure $1 \mathrm{~d}$ ). Thus, the $\mathrm{Cu}$ atoms must be more energy favorable at $\mathrm{Sb}$ sites than at the van der Waals gaps in these p-type $\mathrm{Bi}_{2} \mathrm{Te}_{3}-\mathrm{Sb}_{2} \mathrm{Te}_{3}$-based alloys. 
(a)

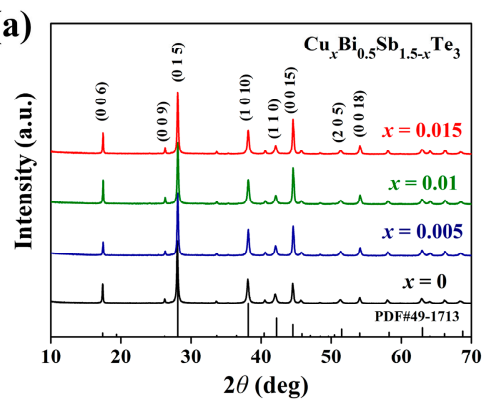

(c)

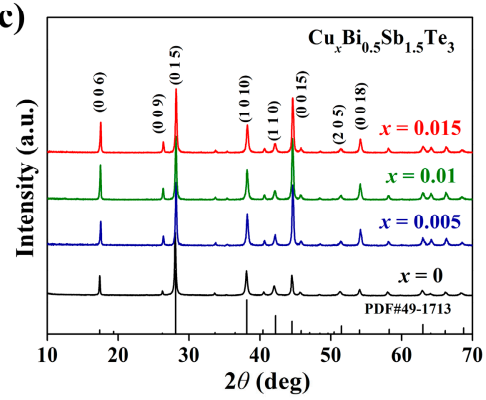

(b)

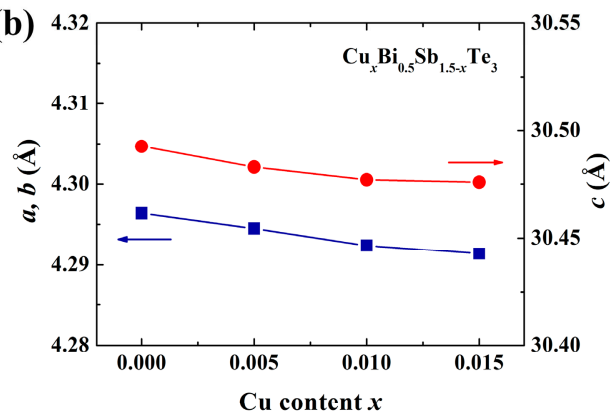

(d)

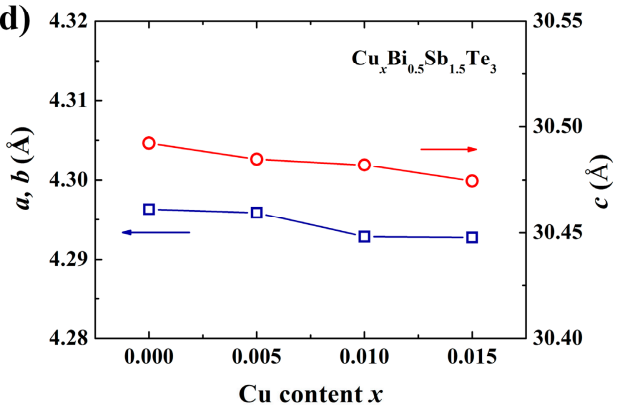

Figure 1. (a) X-ray diffraction patterns and (b) refined lattice parameters for nominal $\mathrm{Cu}$-doped $\mathrm{Cu}_{x} \mathrm{Bi}_{0.5} \mathrm{Sb}_{1.5-x} \mathrm{Te}_{3}(x=0,0.005,0.01,0.015)$ samples; (c) $\mathrm{X}$-ray diffraction patterns and (d) refined lattice parameters for nominal $\mathrm{Cu}$-intercalating $\mathrm{Cu}_{x} \mathrm{Bi}_{0.5} \mathrm{Sb}_{1.5} \mathrm{Te}_{3}(x=0,0.005,0.01,0.015)$ samples.

The occupying position of $\mathrm{Cu}$ atoms in $\mathrm{Bi}_{0.5} \mathrm{Sb}_{1.5} \mathrm{Te}_{3}$ samples can also be identified by transmission electronic microscope (TEM) characterization. Figure 2a,b displays the regular (009) plane images for $\mathrm{Bi}_{0.5} \mathrm{Sb}_{1.5} \mathrm{Te}_{3}$ and $\mathrm{Cu}_{0.005} \mathrm{Bi}_{0.5} \mathrm{Sb}_{1.495} \mathrm{Te}_{3}$, respectively. If $\mathrm{Cu}$ atoms go to the van der Waals gaps, the (00l) plane distance will be expanded, which is the scenario observed in Cu-intercalated n-type $\mathrm{Bi}_{2} \mathrm{Te}_{2.7} \mathrm{Se}_{0.3}$ by Liu et al. [10]. If $\mathrm{Cu}$ atoms go to the $\mathrm{Sb}$ sites, the (00l) plane distance will shrink. Thus, we compared the distance of 29 fringes in the (009) plane images for both $\mathrm{Bi}_{0.5} \mathrm{Sb}_{1.5} \mathrm{Te}_{3}$ and $\mathrm{Cu}_{0.005} \mathrm{Bi}_{0.5} \mathrm{Sb}_{1.495} \mathrm{Te}_{3}$. The total distance of these 29 fringes in $\mathrm{Cu}_{0.005} \mathrm{Bi}_{0.5} \mathrm{Sb}_{1.495} \mathrm{Te}_{3}$ is only $9.22 \mathrm{~nm}$, which is quite smaller than that in $\mathrm{Bi}_{0.5} \mathrm{Sb}_{1.5} \mathrm{Te}_{3}(9.40 \mathrm{~nm})$. This proves that $\mathrm{Cu}$ atoms enter the $\mathrm{Sb}$ sites rather than the van der Waals gaps in the $\mathrm{Cu}_{x} \mathrm{Bi}_{0.5} \mathrm{Sb}_{1.5-x} \mathrm{Te}_{3}$ samples, which is consistent with the contracted lattice parameters obtained by the above XRD refinement. Interestingly, these $\mathrm{Cu}$ atoms at $\mathrm{Sb}$ sites induce significant alternations on the microstructures. Figure $2 \mathrm{c}$ shows the low-magnification TEM image of the undoped $\mathrm{Bi}_{0.5} \mathrm{Sb}_{1.5} \mathrm{Te}_{3}$ matrix. The electron diffraction pattern obtained from the circumvented area demonstrates a typical single crystal-like character. This phenomenon is quite different from that in $\mathrm{Cu}_{0.005} \mathrm{Bi}_{0.5} \mathrm{Sb}_{1.495} \mathrm{Te}_{3}$. As shown in Figure $2 \mathrm{~d}$, the electron diffraction pattern obtained from the circumvented area in $\mathrm{Cu}_{0.005} \mathrm{Bi}_{0.5} \mathrm{Sb}_{1.495} \mathrm{Te}_{3}$ shows typical polycrystalline rings, which could be indexed with standard planes in $\mathrm{Bi}_{0.5} \mathrm{Sb}_{1.5} \mathrm{Te}_{3}$ system. These polycrystalline rings indicate that there are numerous nanograins inside this area. The high-magnification TEM image shown in Figure 2e further proves that the $\mathrm{Cu}$-doped material is indeed composed of nanoscale grains with coherent grain boundaries. The creation of numerous nanograins should be caused by the doped $\mathrm{Cu}$ atoms at the $\mathrm{Sb}$ sites (see the signal of $\mathrm{Cu}$ elements detected by energy dispersive spectrometer in Figure 2f). The discrepancy in atomic radius between $\mathrm{Cu}^{2+}(135 \mathrm{pm})$ and $\mathrm{Sb}^{3+}(145 \mathrm{pm})$, as well as their different electronegativities and valence states, induce the formation of numerous lattice distortions (see Figure $2 \mathrm{~g}, \mathrm{~h})$. Once the lattice distortions exceed the permitted level, dislocations and grain boundaries will be created to release the strain energy, leading to the formation of numerous nanograins, as shown in Figure 2e. These lattice defects will strengthen the scattering to low-frequency heat-carrying phonons, which is expected to greatly lower the lattice thermal conductivity. Theoretically, various kinds of defects—such as antisite defect, dislocation, and/or vacancies-may exist in $\mathrm{Bi}_{2} \mathrm{Te}_{3}-\mathrm{Sb}_{2} \mathrm{Te}_{3}$-based 
materials [14]. However, in this study, we used a long annealing process time to try to obtain samples near the equilibrium state. In such a case, the formation of various defects is greatly suppressed. All our data show that the $\mathrm{Cu}$ atoms are mainly doped at the $\mathrm{Sb}$ sites and promote nanocrystallization.
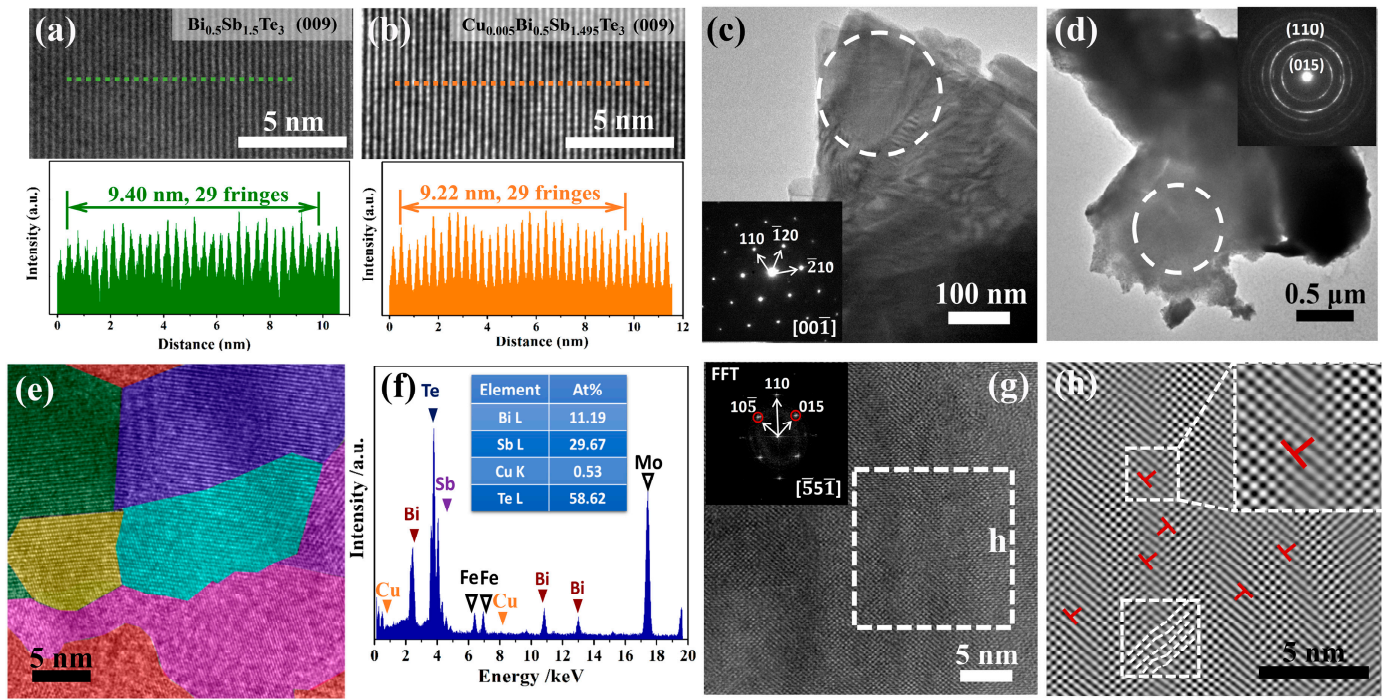

Figure 2. The total distances of 29 fringes in the regular (009) plane TEM images for (a) $\mathrm{Bi}_{0.5} \mathrm{Sb}_{1.5} \mathrm{Te}_{3}$ and (b) $\mathrm{Cu}_{0.005} \mathrm{Bi}_{0.5} \mathrm{Sb}_{1.495} \mathrm{Te}_{3}$. Low-magnification TEM images for (c) $\mathrm{Bi}_{0.5} \mathrm{Sb}_{1.5} \mathrm{Te}_{3}$ matrix and (d) $\mathrm{Cu}_{0.005} \mathrm{Bi}_{0.5} \mathrm{Sb}_{1.495} \mathrm{Te}_{3}$. The insets are the corresponding electron diffraction patterns obtained from the circumvented areas. (e) Nanograins with coherent grain boundaries in $\mathrm{Cu}_{0.005} \mathrm{Bi}_{0.5} \mathrm{Sb}_{1.495} \mathrm{Te}_{3}$; (f) The energy dispersive spectrum (EDS) analysis on the circumvented area in Figure $2 \mathrm{~d}$. The signals of Mo and Fe are from Mo grids and sample stage; (g) HRTEM image of $\mathrm{Cu}_{0.005} \mathrm{Bi}_{0.5} \mathrm{Sb}_{1.495} \mathrm{Te}_{3}$. The inset shows the fast Fourier transferred (FFT) image; (h) Inverse fast Fourier transferred (IFFT) image of planes (015) and (105) in the marked square region in Figure $2 \mathrm{~g}$, in which lots of lattice distortions and edge dislocations are observed.

The bismuth telluride-based materials possess a typical layered crystal structure, and thus the sintered polycrystalline samples usually show oriented plane alignment and anisotropic TE transport properties [15]. In this manuscript, we will just show the electrical and thermal transports along the direction parallel to the sintering press because this direction shows better TE properties. Figure 3a-c shows the electrical transport properties for all $\mathrm{Cu}_{x} \mathrm{Bi}_{0.5} \mathrm{Sb}_{1.5-x} \mathrm{Te}_{3}$ samples. With increasing $\mathrm{Cu}$ content, the $\sigma$ values are gradually increased. At $300 \mathrm{~K}$, the $\sigma$ for $\mathrm{Cu}_{0.005} \mathrm{Bi}_{0.5} \mathrm{Sb}_{1.495} \mathrm{Te}_{3}$ is about $13.7 \times 10^{4} \mathrm{Sm}^{-1}$, almost 3.5 times larger than that in the matrix compound. Correspondingly, the $S$ values near room temperature are greatly reduced in $\mathrm{Cu}$-containing samples. Moreover, in the $\mathrm{Cu}_{x} \mathrm{Bi}_{0.5} \mathrm{Sb}_{1.5-x} \mathrm{Te}_{3}$ system, the peak temperature of $S$ is shifted to higher temperatures for the sample with greater $\mathrm{Cu}$ content. In p-type $\mathrm{Bi}_{0.5} \mathrm{Sb}_{1.5} \mathrm{Te}_{3}$ materials, if $\mathrm{Cu}$ atoms substitute the $\mathrm{Sb}$ atoms, the hole concentration should be enhanced because $\mathrm{Cu}$ has fewer electrons in the outermost orbital than $\mathrm{Sb}$ (see the dashed line in Figure 3c). This speculation is consistent with the measurement results (square symbols) presented in Figure $3 \mathrm{c}$, which shows that the Hall hole concentration $p_{\mathrm{H}}$ increases when increasing the $\mathrm{Cu}$-doping content. For comparison, we also show the $S, \sigma$, and $p_{\mathrm{H}}$ data for the nominal $\mathrm{Cu}$-intercalated $\mathrm{Cu}_{x} \mathrm{Bi}_{0.5} \mathrm{Sb}_{1.5} \mathrm{Te}_{3}$ samples in Figure 3a-c. Furthermore, the measured electrical transports in $\mathrm{Cu}_{x} \mathrm{Bi}_{0.5} \mathrm{Sb}_{1.5} \mathrm{Te}_{3}$ go against the expectation that the $\mathrm{Cu}$ atoms enter the van der Waals gap and introduce additional electrons ( 0.65 electrons per $\mathrm{Cu}$ atom) to reduce $p_{\mathrm{H}}$ and $\sigma$ (see the dotted line in Figure 3c) [9]. Thus, the presented electrical transport properties further prove that $\mathrm{Cu}$ atoms are doped at the $\mathrm{Sb}$ sites in p-type $\mathrm{Bi}_{0.5} \mathrm{Sb}_{1.5} \mathrm{Te}_{3}$. These $\mathrm{Cu}$-dopants can suppress the intrinsic excitation and shift its occurring temperature to high temperatures, thereby leading to the improved $S$ values in Cu-containing samples above $500 \mathrm{~K}$ (see Figure 3b). 

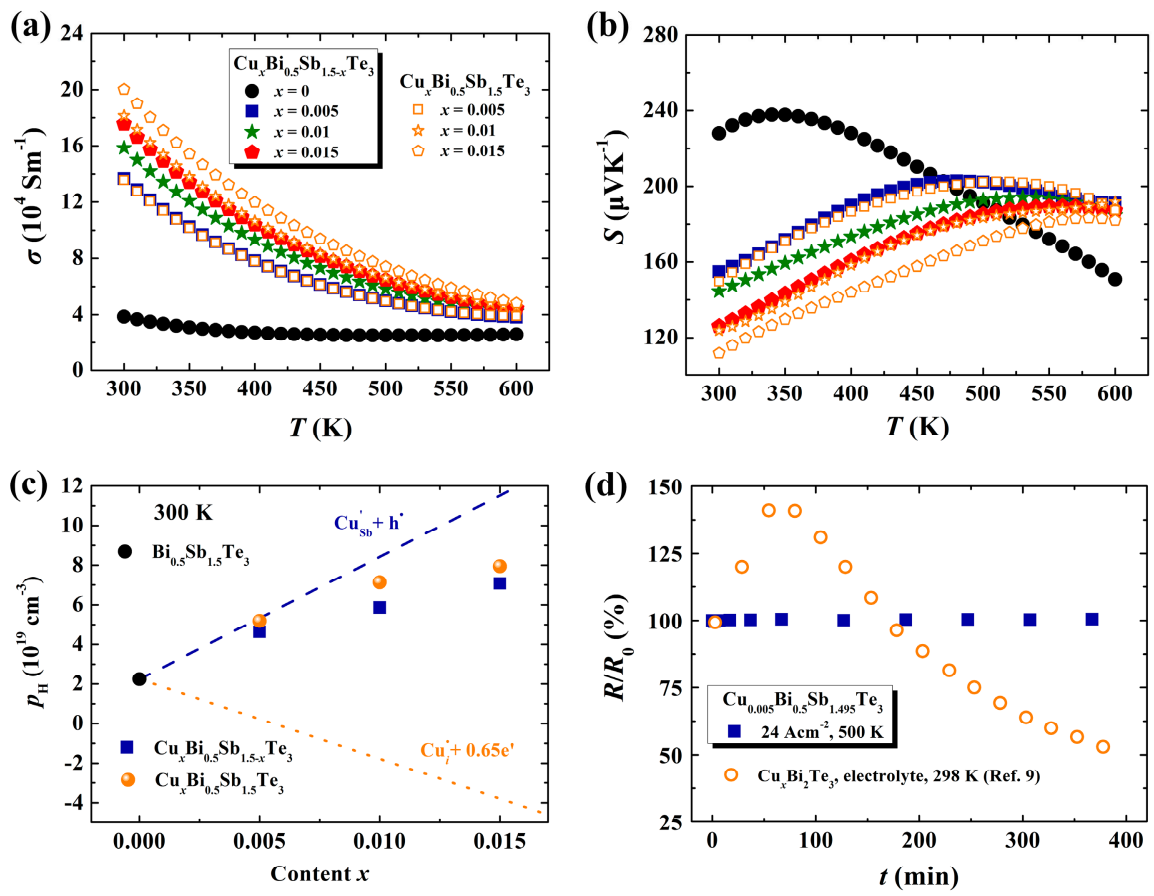

Figure 3. Temperature dependences of (a) electrical conductivity $\sigma$ and (b) Seebeck coefficient $S$ for nominal $\mathrm{Cu}$-doped $\mathrm{Cu}_{x} \mathrm{Bi}_{0.5} \mathrm{Sb}_{1.5-x} \mathrm{Te}_{3}$ samples and nominal $\mathrm{Cu}$-intercalated $\mathrm{Cu}_{x} \mathrm{Bi}_{0.5} \mathrm{Sb}_{1.5} \mathrm{Te}_{3}$ samples. The $\sigma$ and $S$ data for $\mathrm{Cu}_{x} \mathrm{Bi}_{0.5} \mathrm{Sb}_{1.5-x} \mathrm{Te}_{3}(x=0, x=0.005)$ are taken from [8]; (c) The measured Hall hole concentration $p_{\mathrm{H}}$ at $300 \mathrm{~K}$ as a function of the nominal $\mathrm{Cu}$ content $x$ for all $\mathrm{Cu}_{x} \mathrm{Bi}_{0.5} \mathrm{Sb}_{1.5-x} \mathrm{Te}_{3}$ and $\mathrm{Cu}_{x} \mathrm{Bi}_{0.5} \mathrm{Sb}_{1.5} \mathrm{Te}_{3}$ samples. The dashed and dotted lines represent the predicated $p_{\mathrm{H}}$ curves by assuming the $\mathrm{Cu}$ atoms at $\mathrm{Sb}$ sites and at the van der Waals gap, respectively; (d) Relative resistance $R / R_{0}$ for $\mathrm{Cu}_{0.005} \mathrm{Bi}_{0.5} \mathrm{Sb}_{1.495} \mathrm{Te}_{3}$ sample under the current density of $24 \mathrm{Acm}^{-2}$ at $500 \mathrm{~K}$. The data of $\mathrm{Cu}$-intercalated p-type $\mathrm{Bi}_{2} \mathrm{Te}_{3}$ reported by McCarthy et al. are also shown for comparison [9].

In bismuth telluride-based materials, the intercalated $\mathrm{Cu}$ atoms in the van der Waals gap usually form very weak interactions with the nearby Te atoms because the Te atoms do not have extra free electrons. McCarthy et al. [9] found that the external electrical field could easily drive the Cu ions into the van der Waals gap of $\mathrm{p}$-type $\mathrm{Bi}_{2} \mathrm{Te}_{3}$. However, these $\mathrm{Cu}$ ions will quickly diffuse out from the material when the external electrical field is removed. Interestingly, in the present $\mathrm{Cu}_{x} \mathrm{Bi}_{0.5} \mathrm{Sb}_{1.5-x} \mathrm{Te}_{3}$ samples, the doped $\mathrm{Cu}$ atoms at the $\mathrm{Sb}$ sites have quite high stability under external electric field. We have stressed an external current of $24 \mathrm{Acm}^{-2}$ on the $\mathrm{Cu}_{0.005} \mathrm{Bi}_{0.5} \mathrm{Sb}_{1.495} \mathrm{Te}_{3}$ sample at $500 \mathrm{~K}$ to check its stability. If $\mathrm{Cu}$ atoms are intercalated in the van der Waals gap, such a large current density will definitely drive the $\mathrm{Cu}$ ions out from the van der Waals gap and then change its resistivity. This method has been successfully applied to characterize the $\mathrm{Cu}$-ion migration behavior in $\mathrm{Cu}_{2} \mathrm{~S}$ ionic conductor [16]. As shown in Figure 3d, under a current density of $24 \mathrm{Acm}^{-2}$, the resistance of the $\mathrm{Cu}_{0.005} \mathrm{Bi}_{0.5} \mathrm{Sb}_{1.495} \mathrm{Te}_{3}$ sample is scarcely changed, proving that the $\mathrm{Cu}$ atoms have high stability under an external electric field. The $\mathrm{Cu}$ atoms occupying $\mathrm{Sb}$ sites could form strong chemical bonds with surrounding Te atoms, resulting in the observed high stability.

The tiny amount of $\mathrm{Cu}$ dopants in $\mathrm{Bi}_{0.5} \mathrm{Sb}_{1.5} \mathrm{Te}_{3}$ scarcely changes the band structure. In principle, the density-of-states effective mass $m^{*}$ that reflects band structure can be simulated by the single parabolic (SPB) model as shown below [17]:

$$
S=\frac{k_{B}}{e}\left(\frac{(5 / 2+\lambda) F_{3 / 2+\lambda}(\eta)}{(3 / 2+\lambda) F_{1 / 2+\lambda}(\eta)}-\eta\right)
$$




$$
\begin{aligned}
& F_{\mathrm{j}}(\eta)=\int_{0}^{\infty} \frac{\xi^{j} d \xi}{1+\exp (\xi-\eta)} \\
& p=4 \pi\left(\frac{2 m^{*} k_{B} T}{h^{2}}\right)^{3 / 2} F_{1 / 2}(\eta)
\end{aligned}
$$

Here, $k_{\mathrm{B}}$ is the Boltzmann constant, $e$ is the elementary charge, $\eta$ is the reduced Fermi level, and $\lambda$ is the scattering parameter and taken as $-1 / 2$ for electron-phonon scattering [18]. $F_{\mathrm{j}}$ is the Fermi integrals calculated by Equation (2). In Equation (3), $p$ is the hole concentration and taken as the measured $p_{\mathrm{H}}$ value, and $h$ is the Planck constant. Figure 4 a presents the theoretical Pisarenko plot at $300 \mathrm{~K}$ by assuming $m^{*}=1.3 m_{\mathrm{e}}\left(m_{\mathrm{e}}\right.$ is the inertia mass of electron). The experimental $S$ data for Cu-doped $\mathrm{Bi}_{0.5} \mathrm{Sb}_{1.5} \mathrm{Te}_{3}$ samples, Cd-doped samples, and some other $\mathrm{Bi}_{0.5} \mathrm{Sb}_{1.5} \mathrm{Te}_{3}$ samples previously reported will fall on this calculated line [19-23], suggesting that all samples possess similar $m^{*}$. This is reasonable, considering the very tiny amount of $\mathrm{Cu}$ - or $\mathrm{Cd}$-doping content used in the present study. These dopants just shift the Fermi level downward without obviously changing the band structure near the Fermi level.
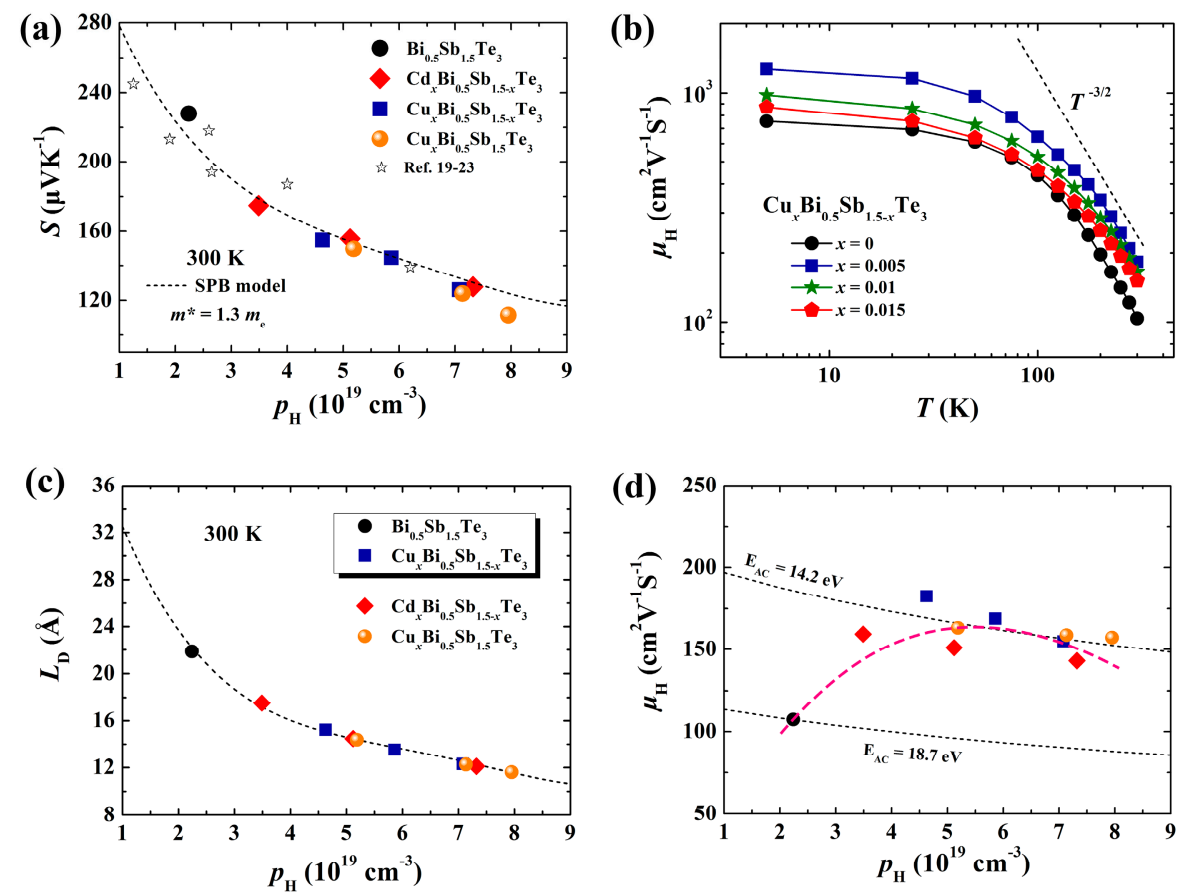

Figure 4. (a) The theoretical and experimental Pisarenko plots for $\mathrm{Cu}$-doped $\mathrm{Bi}_{0.5} \mathrm{Sb}_{1.5} \mathrm{Te}_{3}$ samples. The data of $\mathrm{Cd}$-doped $\mathrm{Bi}_{0.5} \mathrm{Sb}_{1.5} \mathrm{Te}_{3}$ samples and some other $\mathrm{Bi}_{0.5} \mathrm{Sb}_{1.5} \mathrm{Te}_{3}$ samples previously reported [19-23] are also shown for comparison; (b) temperature dependence of Hall mobility $\mu_{\mathrm{H}}$ for Cu-doped samples; (c) the Hall hole concentration $p_{\mathrm{H}}$ dependences of the calculated Debye screen length $L_{\mathrm{D}}$; and (d) the mobility $\mu_{\mathrm{H}}$ for $\mathrm{Cu}$-doped $\mathrm{Bi}_{0.5} \mathrm{Sb}_{1.5} \mathrm{Te}_{3}$ samples. The data of Cd-doped $\mathrm{Bi}_{0.5} \mathrm{Sb}_{1.5} \mathrm{Te}_{3}$ samples are included for comparison. The dashed line in (d) is provided as a guide for eyes. The dotted lines in (d) represent the theoretical trends predicted by acoustic phonon scattering mechanism with different deformation potential $E_{\mathrm{AC}}$.

The existence of numerous nanograins in $\mathrm{Cu}$-doped samples is expected to strengthen the carrier scattering and reduce the carrier mobility $\left(\mu_{\mathrm{H}}\right)$. Surprisingly, Figure $4 \mathrm{~b}$ shows that the Cu-doped samples possess much higher $\mu_{\mathrm{H}}$ than the undoped $\mathrm{Bi}_{0.5} \mathrm{Sb}_{1.5} \mathrm{Te}_{3}$. At room temperature, $\mu_{\mathrm{H}}$ for $\mathrm{Cu}_{0.005} \mathrm{Bi}_{0.5} \mathrm{Sb}_{1.495} \mathrm{Te}_{3}$ is $182.6 \mathrm{~cm}^{2} \mathrm{~V}^{-1} \mathrm{~S}^{-1}$, which is about $70 \%$ higher than that of the undoped $\mathrm{Bi}_{0.5} \mathrm{Sb}_{1.5} \mathrm{Te}_{3}$. Especially, such enhanced $\mu_{\mathrm{H}}$ values are observed over the entire measured temperature range. These enhanced carrier mobilities might benefit from the weakened ionized impurity scattering 
and acoustic phonon scattering. Generally, the total mobility $\mu$, including these two scattering mechanisms, satisfy the Matthiessen's rule [24]:

$$
\frac{1}{\mu}=\frac{1}{\mu_{\mathrm{I}}}+\frac{1}{\mu_{\mathrm{AC}}}
$$

where $\mu_{\mathrm{I}}$ and $\mu_{\mathrm{AC}}$ is the mobility for ionized impurity scattering and acoustic phonon scattering, respectively. Even in the $\mathrm{Bi}_{0.5} \mathrm{Sb}_{1.5} \mathrm{Te}_{3}$, the ionized impurity scattering still exists, because there are numerous intrinsic antisite defects $\left(\mathrm{Sb}_{\mathrm{Te}}^{\prime}\right)$ or vacancies in the material due to their low formation energies [14]. Generally, the corresponding mobility $\left(\mu_{\mathrm{I}}\right)$ of ionized impurity scattering could be expressed as [25]:

$$
\mu_{\mathrm{I}}=\frac{64 \sqrt{\pi} \varepsilon^{2}\left(2 k_{\mathrm{B}} T\right)^{\frac{3}{2}}}{N_{\mathrm{I}} e^{3} \sqrt{m_{\mathrm{s}}^{*} f\left(L_{D}\right)}}
$$

Herein, $\varepsilon$ is the dielectric constant and taken as 75 [26]. The relation between density-of-states effective mass $m^{*}$ and single valley effective mass $m_{s}^{*}$ satisfies $m^{*}=N_{v}^{2 / 3} m_{s}^{*}$, where $N_{v}$ is valence band degeneracy and taken as 6 for $\mathrm{Bi}_{2} \mathrm{Te}_{3}$-based materials [5,27]. $N_{\mathrm{I}}$ is the ionized impurity concentration. Dimensionless $f\left(L_{D}\right)$ in Equation 5 can be expressed as:

$$
f\left(L_{D}\right)=\ln \left(\frac{12 m_{\mathrm{s}}^{*} k_{\mathrm{B}} T L_{D}^{2}}{\hbar^{2}}+1\right)-\frac{12 m_{\mathrm{s}}^{*} k_{\mathrm{B}} T L_{D}^{2}}{12 m_{\mathrm{s}}^{*} k_{\mathrm{B}} T L_{D}^{2}+\hbar^{2}}
$$

where $\hbar$ is reduced Planck constant. $L_{D}$ is Debye screen length, with the formula:

$$
L_{D}=\sqrt{\frac{\varepsilon k_{B} T}{p e^{2}}}
$$

The shorter $L_{\mathrm{D}}$ means a smaller Coulomb potential around ionized impurity and thereby a weaker effect on the carrier transports [25]. Based on the Equations (5)-(7), $\mu_{\mathrm{I}}$ is simultaneously determined by the ionized impurity concentration $N_{I}$ and Debye screen length $L_{D}$. As shown in Figure $4 c$, the $L_{D}$ value in the $\mathrm{Bi}_{0.5} \mathrm{Sb}_{1.5} \mathrm{Te}_{3}$ sample is around $21.9 \AA$ at $300 \mathrm{~K}$. However, in the $\mathrm{Cu}_{x} \mathrm{Bi}_{0.5} \mathrm{Sb}_{1.5-x} \mathrm{Te}_{3}$ samples, the $L_{\mathrm{D}}$ values are reduced to 12.3-15.2 $\AA$, depending on the hole concentrations. Thus, although $\mathrm{Cu}$-doping slightly increases $N_{\mathrm{I}}$, the reduced $L_{\mathrm{D}}$ still leads to the weakened ionized impurity scattering to the carriers.

Besides the ionized impurity scattering, the acoustic phonon scattering to the carriers is also weakened in the $\mathrm{Cu}$-doped samples. As shown in Figure $4 \mathrm{~b}$, the acoustic phonon scattering $\left(\mu_{\mathrm{H}} \propto T^{-3 / 2}\right)$ is the dominant scattering mechanism for all $\mathrm{Cu}_{x} \mathrm{Bi}_{0.5} \mathrm{Sb}_{1.5-x} \mathrm{Te}_{3}$ samples around room temperature. The mobility $\left(\mu_{\mathrm{AC}}\right)$ for acoustic phonon scattering in the SPB model can be written as [27]:

$$
\mu_{\mathrm{AC}}=\frac{(8 \pi)^{\frac{1}{2}} e \hbar^{4} \rho v^{2}}{3 E_{\mathrm{AC}}^{2}\left(m_{\mathrm{S}}^{*}\right)^{5 / 2}\left(k_{\mathrm{B}} T\right)^{3 / 2}} \psi(\eta)
$$

where $\rho$ is density, $v$ is the longitudinal velocity of sound and taken as $2884 \mathrm{~m} / \mathrm{s}$ [28], and $E_{\mathrm{AC}}$ is the deformation potential, which is generally used to evaluate the intensity of electron-phonon interaction. $\psi(\eta)$ in Equation (8) is a monotonous decreasing function with reduced Fermi level $(\eta)$ or hole concentration. It can be expressed as:

$$
\psi(\eta)=\frac{3 \sqrt{\pi}}{4} \frac{2 \lambda+3 / 2}{\lambda+3 / 2} \frac{1}{\Gamma(\lambda+5 / 2)} \frac{F_{2 \lambda+1 / 2}(\eta)}{F_{\lambda+1 / 2}(\eta)} .
$$

Herein, the increased hole concentration by $\mathrm{Cu}$ doping reduces $\psi(\eta)$ and thus carrier mobility with the magnitude within $9 \%-25 \%$ as compared with undoped matrix. However, by using the $\mu_{\mathrm{H}}$ data at $300 \mathrm{~K}$, Equations (8) and (9) (see Figure 4d) show that $\mathrm{Cu}$-doping reduces the deformation 
potential $E_{\mathrm{AC}}$ from $18.7 \mathrm{eV}$ to $14.2 \mathrm{eV}$, which could enhance mobility by more than $70 \%$. Thus, these two effects show that the interaction between carriers and phonons is greatly lessened in $\mathrm{Cu}$-doped samples. Combining the weakened ionized impurity scattering mentioned above, the enhanced carrier mobilities, observed in Figure 4b, in Cu-doped samples can be well explained. As shown in Figure 4c-d, the reduced $L_{\mathrm{D}}$ and $E_{\mathrm{AC}}$ can also account for the abnormal enhanced carrier mobilities in the Cd-doped $\mathrm{Cd}_{x} \mathrm{Bi}_{0.5} \mathrm{Sb}_{1.5-x} \mathrm{Te}_{3}$ system.

Figure 5 a displays the temperature dependence of total thermal conductivity $\kappa$ for $\mathrm{Cu}$-doped $\mathrm{Cu}_{x} \mathrm{Bi}_{0.5} \mathrm{Sb}_{1.5-x} \mathrm{Te}_{3}$ samples. The $\kappa$ includes three parts, termed as the carrier thermal conductivity $\left(\kappa_{\mathrm{e}}\right)$, lattice thermal conductivity $\left(\kappa_{\mathrm{L}}\right)$, and bipolar thermal conductivity $\left(\kappa_{\mathrm{b}}\right) \cdot \kappa_{\mathrm{e}}$ is calculated according to Wiedemann-Franz law $\left(\kappa_{\mathrm{e}}=L \sigma T\right.$, where $L$ is the Lorenz number and taken as $\left.1.6 \times 10^{-8} \mathrm{~V}^{2} \mathrm{~K}^{-2}\right)$ [29]. In this system, the substitution of $\mathrm{Cu}$ at the $\mathrm{Sb}$ sites significantly improves the electrical conductivity by simultaneously enhancing $p_{\mathrm{H}}$ and $\mu_{\mathrm{H}}$. Thus, the $\kappa_{\mathrm{e}}$ in $\mathrm{Cu}$-doped samples is much higher than that in $\mathrm{Bi}_{0.5} \mathrm{Sb}_{1.5} \mathrm{Te}_{3}$ matrix. Then, although the $\kappa_{\mathrm{L}}$ values in $\mathrm{Cu}$-doped samples are reduced, the total $\kappa$ near room temperature is enhanced. Because $\mathrm{Bi}_{0.5} \mathrm{Sb}_{1.5} \mathrm{Te}_{3}$ has a very narrow band gap, around $0.2 \mathrm{eV}$, electrons are easily excited from the valence band to conduction band to form hole-electron pairs. The recombination of these hole-electron pairs releases extra heat and induces the remarkable $\kappa_{\mathrm{b}}$ in the $\mathrm{Cu}$-free $\mathrm{Bi}_{0.5} \mathrm{Sb}_{1.5} \mathrm{Te}_{3}$ sample above $350 \mathrm{~K}$. Doping $\mathrm{Cu}$ into the system effectively suppresses the $\kappa_{\mathrm{b}}$ via reducing minor carrier concentration (electrons) [8], which can account for the observed low $\kappa$ values at high temperature in $\mathrm{Cu}$-doped $\mathrm{Bi}_{0.5} \mathrm{Sb}_{1.5} \mathrm{Te}_{3}$ samples.
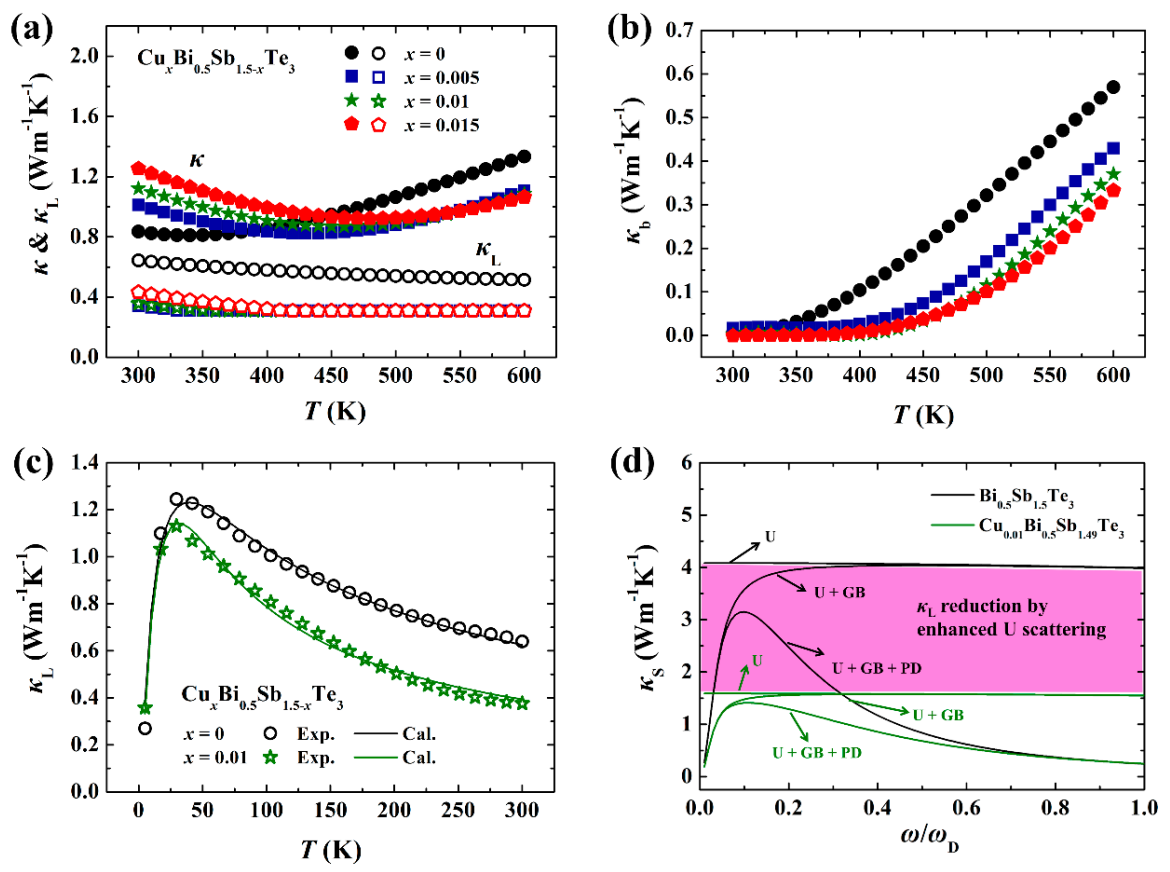

Figure 5. Temperature dependences of (a) total thermal conductivity $\kappa$ (and lattice thermal conductivity $\kappa_{\mathrm{L}}$ ) and (b) bipolar thermal conductivity $\kappa_{\mathrm{b}}$ for $\mathrm{Cu}_{x} \mathrm{Bi}_{0.5} \mathrm{Sb}_{1.5-x} \mathrm{Te}_{3}$ samples. The data for $x=0$ and $x=0.005$ are taken from [8]; (c) Low-temperature $\kappa_{\mathrm{L}}$ for $\mathrm{Bi}_{0.5} \mathrm{Sb}_{1.5} \mathrm{Te}_{3}$ and $\mathrm{Cu}_{0.01} \mathrm{Bi}_{0.5} \mathrm{Sb}_{1.49} \mathrm{Te}_{3}$. The solid lines are the fitting results by Debye model; (d) Contribution of phonon-phonon Umklapp scattering $(\mathrm{U})$, point defects scattering (PD), and grain boundary scattering (GB) to the total $\kappa_{\mathrm{L}}$ for $\mathrm{Bi}_{0.5} \mathrm{Sb}_{1.5} \mathrm{Te}_{3}$ and $\mathrm{Cu}_{0.01} \mathrm{Bi}_{0.5} \mathrm{Sb}_{1.49} \mathrm{Te}_{3}$ at $300 \mathrm{~K}$. The color-filled area represents the reduction of $\kappa_{\mathrm{L}}$ by enhanced $\mathrm{U}$ scattering in $\mathrm{Cu}_{0.01} \mathrm{Bi}_{0.5} \mathrm{Sb}_{1.49} \mathrm{Te}_{3}$. 
The very low $\kappa_{\mathrm{L}}$ values approaching the theoretical minimum value $\left(0.31 \mathrm{Wm}^{-1} \mathrm{~K}^{-1}\right)$ in $\mathrm{Cu}$-doped $\mathrm{Bi}_{0.5} \mathrm{Sb}_{1.5} \mathrm{Te}_{3}$ samples are very interesting [30]. We fitted the low-temperature $\kappa_{\mathrm{L}}$ of $\mathrm{Bi}_{0.5} \mathrm{Sb}_{1.5} \mathrm{Te}_{3}$ and $\mathrm{Cu}_{0.01} \mathrm{Bi}_{0.5} \mathrm{Sb}_{1.49} \mathrm{Te}_{3}$ by the Debye model, in which $\kappa_{\mathrm{L}}$ is expressed by [31]:

$$
\kappa_{\mathrm{L}}=\frac{k_{\mathrm{B}}}{2 \pi^{2} v}\left(\frac{k_{\mathrm{B}}}{\hbar}\right)^{3} T^{3} \int_{0}^{\theta_{\mathrm{D}} / T} \frac{x^{4} e^{x}}{\tau_{t}^{-1}\left(e^{x}-1\right)^{2}} d x
$$

and the spectral lattice thermal conductivity $\kappa_{\mathrm{S}}$ can be expressed by [32]:

$$
\kappa_{\mathrm{S}}=\frac{k_{\mathrm{B}}}{2 \pi^{2} v}\left(\frac{k_{\mathrm{B}}}{\hbar}\right)^{3} T^{3} \frac{x^{4} e^{x}}{\tau_{t}^{-1}\left(e^{x}-1\right)^{2}}
$$

where average sound speed $v$ is taken as $2930 \mathrm{~m} / \mathrm{s}$ [33]. In this equation, $x=\hbar \omega / k_{\mathrm{B}} T$, and $\omega$ is the phonon frequency. The total relaxation time for $\mathrm{Bi}_{2} \mathrm{Te}_{3}$-based materials is given by:

$$
\tau_{t}^{-1}=\tau_{B}^{-1}+\tau_{P}^{-1}+\tau_{U}^{-1}=\frac{v}{d}+P \omega^{4}+U \omega^{2} T e^{-\theta_{D} / 3 T}
$$

where $\theta_{\mathrm{D}}$ is Debye temperature and taken as $160 \mathrm{~K}$ [33]. $\tau_{B}, \tau_{P}$, and $\tau_{U}$ are the relaxation time for grain boundary scattering $(\mathrm{GB})$, point defect scattering $(\mathrm{PD})$, and phonon-phonon Umklapp scattering $(\mathrm{U})$, respectively [34]. $d$ is the grain size, and $P$ and $U$ are the coefficients to evaluate the intensity of each phonon scattering mechanism. By fitting the low-temperature $\kappa_{\mathrm{L}}$, these parameters can be obtained (see Table 1). Figure $5 \mathrm{~d}$ shows the integral area of reduced $\kappa_{\mathrm{L}}$ by each individual scattering mechanism. Because the exotic $\mathrm{Cu}$ atoms interrupt the periodicity of lattice vibration (see the TEM results shown in Figure 2) and bring stronger anharmonicity, the integral area of reduced $\kappa_{\mathrm{L}}$ by $\mathrm{U}$ process is greatly reduced. Thus, the total $\kappa_{\mathrm{L}}$ in $\mathrm{Cu}_{0.01} \mathrm{Bi}_{0.5} \mathrm{Sb}_{1.495} \mathrm{Te}_{3}$ is much lower than the $\mathrm{Cu}$-free $\mathrm{Bi}_{0.5} \mathrm{Sb}_{1.5} \mathrm{Te}_{3}$.

Table 1. Fitting parameters for low-temperature lattice thermal conductivity by using the Debye model.

\begin{tabular}{ccc}
\hline $\mathbf{C u}_{x} \mathbf{B i}_{\mathbf{0 . 5}} \mathbf{S b}_{1.5-x} \mathbf{T e}_{3}$ & $x=\mathbf{0}$ & $\boldsymbol{x}=\mathbf{0 . 0 1}$ \\
\hline$d(\mu \mathrm{m})$ & 2.05 & 1.52 \\
$P\left(10^{-41} \mathrm{~s}^{3}\right)$ & 8.06 & 7.09 \\
$U\left(10^{-18} \mathrm{sK}^{-1}\right)$ & 9.14 & 23.50 \\
\hline
\end{tabular}

Figure 6 shows the temperature dependence of TE figure of merit $z T$ for $\mathrm{Cu}$-doped $\mathrm{Cu}_{x} \mathrm{Bi}_{0.5} \mathrm{Sb}_{1.5-x} \mathrm{Te}_{3}$ samples. The undoped $\mathrm{Bi}_{0.5} \mathrm{Sb}_{1.5} \mathrm{Te}_{3}$ matrix displays a maximum $z T$ around 0.8 at $330 \mathrm{~K}$. Due to the combined effects of enhanced hole concentration, improved carrier mobility, reduced lattice thermal conductivity, and bipolar thermal conductivity, the maximum $z T$ is significantly improved to 1.4. In addition, the suppressed intrinsic excitation in $\mathrm{Cu}$-doped $\mathrm{Cu}_{x} \mathrm{Bi}_{0.5} \mathrm{Sb}_{1.5-x} \mathrm{Te}_{3}$ successfully shifts the peak $z T$ towards high temperatures of $430-470 \mathrm{~K}$. Combining the good stability under electric field, these $\mathrm{Cu}$-doped $\mathrm{Cu}_{x} \mathrm{Bi}_{0.5} \mathrm{Sb}_{1.5-x} \mathrm{Te}_{3}$ samples show great potential in applications such as low-grade waste heat recovery. 


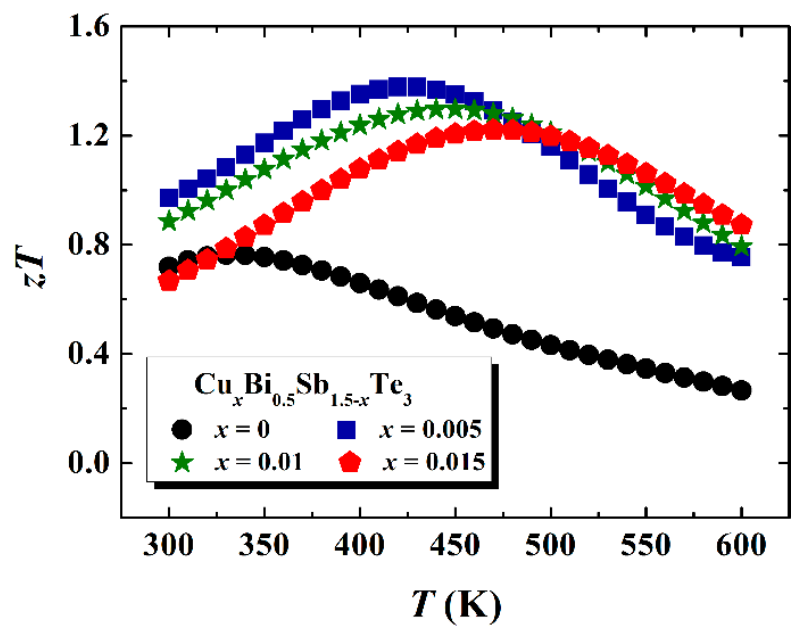

Figure 6. Temperature dependence of figure of merit $z T$ for $\mathrm{Cu}$-doped samples. The data for $x=0$ and $x=0.005$ are taken from [8].

\section{Materials and Methods}

High purity elements Bi (99.999\%), Sb (99.999\%), Te (99.999\%), Cu (99.999\%), and Cd (99.999\%) were used to synthesize the samples according to the stoichiometric composition $\mathrm{Cu}_{x} \mathrm{Bi}_{0.5} \mathrm{Sb}_{1.5-x} \mathrm{Te}_{3}$ $\left(x=0.005,0.01,0.015\right.$, ) and $\mathrm{Cd}_{x} \mathrm{Bi}_{0.5} \mathrm{Sb}_{1.5-x} \mathrm{Te}_{3}(x=0.005,0.01,0.015)$. The samples with the compositions of $\mathrm{Cu}_{x} \mathrm{Bi}_{0.5} \mathrm{Sb}_{1.5} \mathrm{Te}_{3}(x=0.005,0.01,0.015)$ were also prepared in this study. These elements were firstly sealed into quartz tubes in vacuum, and then melt at $1373 \mathrm{~K}$ for $12 \mathrm{~h}$. After quenching into a water bath, they were placed into furnace again and annealed at $673 \mathrm{~K}$ for 5 days. Subsequently, the grown ingots were ground to fine powders in agate mortar by hand. These obtained powders were then consolidated by spark plasma sintering (SPS) to form dense cylinders with a height of about $12 \mathrm{~mm}$, which are used to characterize the TE properties along the directions parallel and perpendicular to the pressing. During the sintering procedures, the powders were filled into graphite die and held at $683 \mathrm{~K}$ for $10 \mathrm{~min}$ under a pressure of $50 \mathrm{MPa}$. High densities ( $>98 \%$ of the theoretical density) for all sintered samples were obtained.

X-ray diffractometer (XRD, D8 ADVANCE, Bruker Co. Ltd., Karlsruhe, Germany) was used to analyze phase purity for powder samples. The microstructures of the prepared powder samples were also observed by high-resolution transmission electronic microscope (HRTEM, JEOL 2100F, Tokyo, Japan). The chemical composition was analyzed by equipped energy dispersive spectrometer (EDS, Oxford Instruments plc, Oxfordshire, UK). Electrical conductivity $(\sigma)$ and Seebeck coefficient $(S)$ above the room temperature were measured by using commercial ZEM-3 (ULVAC Co. Ltd, Kanagawa, Japan) apparatus. The stability under large current density was evaluated by in situ measured resistance in a modified thermal dilatometer (DIL 402c, Netzch Co. Ltd., Selb, Germany). Thermal conductivity $(\kappa)$ is the product of thermal diffusivity $(D)$, heat capacity $\left(C_{\mathrm{p}}\right)$, and density $(\rho)$. The $D$ was measured by commercial instrument (LFA 457, Netzch Co. Ltd., Selb, Germany) based on laser flash method. The $C_{\mathrm{p}}$ was measured by using differential scanning calorimetry (DSC 200 F3, Netzch Co. Ltd., Selb, Germany). The $\rho$ was measured by the Archimedes method. The low-temperature Hall coefficient $\left(R_{\mathrm{H}}\right), \sigma$, and $\kappa$ were measured in Physical Property Measurement System (PPMS, Quantum Design, San Diego, CA, USA). $R_{\mathrm{H}}$ was measured by sweeping magnetic field to $3 \mathrm{~T}$ in both positive and negative directions. The Hall carrier concentration is calculated by $p_{\mathrm{H}}=1 / e R_{\mathrm{H}}$, and the mobility $\left(\mu_{\mathrm{H}}\right)$ can be estimated by $\mu_{\mathrm{H}}=\sigma R_{\mathrm{H}}$.

\section{Conclusions}

In this study, the occupancy site of $\mathrm{Cu}$ atoms in p-type $\mathrm{Bi}_{0.5} \mathrm{Sb}_{1.5} \mathrm{Te}_{3}$ materials was studied and their roles on TE properties were illustrated. Via systematical characterizations on the lattice 
parameters, microstructures, electrical transports, and material stabilities, the possibility of $\mathrm{Cu}$ intercalation in p-type $\mathrm{Bi}_{0.5} \mathrm{Sb}_{1.5} \mathrm{Te}_{3}$ materials has been excluded and the position of $\mathrm{Cu}$ is identified as doping at the $\mathrm{Sb}$ sites. These $\mathrm{Cu}$ dopants not only increase the hole concentration, but also improve the hole mobility by weakening the acoustic phonon scattering and ionized impurity scattering on carriers. Thus, significantly enhanced electrical conductivities are achieved in Cu-doped $\mathrm{Bi}_{0.5} \mathrm{Sb}_{1.5} \mathrm{Te}_{3}$ materials. Furthermore, the $\mathrm{Cu}$ dopants can significantly reduce the lattice thermal conductivity and bipolar thermal conductivity by inducing nanostructural defects and suppressing the intrinsic excitation. Combining the excellent electrical transport properties and low lattice thermal conductivities, the maximum figure of merit $z T$ around 1.4 at $430 \mathrm{~K}$ has been achieved in $\mathrm{Cu}$-doped samples, almost $70 \%$ higher than undoped $\mathrm{Bi}_{0.5} \mathrm{Sb}_{1.5} \mathrm{Te}_{3}$ matrix.

Acknowledgments: This work was supported by National Basic Research Program of China (973-program) under Project No. 2013CB632501, National Natural Science Foundation of China (NSFC) under the No. 11234012, the International S\&T Cooperation Program of Shanghai (Grant No. 16520721400), and International S\&T Cooperation Program of China (2015DFA51050).

Author Contributions: In this study, Feng Hao designed and performed the experiments; Qingfeng Song contributed the XRD refinement; Ping Lu contributed TEM data; Dudi Ren provided the guidance in properties measurement. Data analysis and interpretation were performed by Feng Hao with the help of Hongyi Chen, Pengfei Qiu, Xun Shi and Lidong Chen. Pengfei Qiu, Xun Shi and Lidong Chen revised this manuscript.

Conflicts of Interest: The authors declare no conflict of interest.

\section{References}

1. Zebarjadi, M.; Esfarjani, K.; Dresselhaus, M.S.; Ren, Z.; Chen, G. Perspectives on thermoelectrics: From fundamentals to device applications. Energy Environ. Sci. 2012, 5, 5147-5162. [CrossRef]

2. Shi, X.; Chen, L. Thermoelectric materials step up. Nat. Mater. 2016, 15, 691-692. [CrossRef] [PubMed]

3. Snyder, G.J.; Toberer, E.S. Complex thermoelectric materials. Nat. Mater. 2008, 7, 105-114. [CrossRef] [PubMed]

4. Shi, X.; Chen, L.; Uher, C. Recent advances in high-performance bulk thermoelectric materials. Int. Mater. Rev. 2016, 61, 379-415. [CrossRef]

5. Nolas, G.S.; Sharp, J.; Goldsmid, H.J. Thermoelectrics: Basic Principles and New Materials Developments; Springer: New York, NY, USA, 2001; pp. 123-131.

6. Goldsmid, H.J.; Sharp, J.W. Estimation of the thermal band gap of a semiconductor from seebeck measurements. J. Electron. Mater. 1999, 28, 869-872. [CrossRef]

7. Yang, J. Theory of Thermal Conductivity. In Thermal Conductivity: Theory, Properties and Application; Tritt, T.M., Ed.; Kluwer Academic/Plenum Publishers: New York, NY, USA, 2004; pp. 3-9.

8. Hao, F.; Qiu, P.; Tang, Y.; Bai, S.; Xing, T.; Chu, H.S.; Zhang, Q.; Lu, P.; Zhang, T.; Ren, D.; et al. High efficiency $\mathrm{Bi}_{2} \mathrm{Te}_{3}$-based materials and devices for thermoelectric power generation between 100 and $300{ }^{\circ} \mathrm{C}$. Energy Environ. Sci. 2016, 9, 3120-3127. [CrossRef]

9. McCarthy, T.A.; Goldsmid, H.J. Electro-deposited copper in bismuth telluride. J. Phys. D Appl. Phys. 1970, 3, 697-706. [CrossRef]

10. Liu, W.; Zhang, Q.Y.; Lan, Y.; Chen, S.; Yan, X.; Zhang, Q.; Wang, H.; Wang, D.Z.; Chen, G.; Ren, Z. Thermoelectric property atudies on $\mathrm{Cu}$-soped n-type $\mathrm{Cu}_{x} \mathrm{Bi}_{2} \mathrm{Te}_{2.7} \mathrm{Se}_{0.3}$ nanocomposites. Adv. Energy Mater. 2011, 1, 577-587. [CrossRef]

11. Chen, T.; Chen, Q.; Schouteden, K.; Huang, W.; Wang, X.; Li, Z.; Miao, F.; Wang, X.; Li, Z.; Zhao, B.; et al. Topological transport and atomic tunnelling-clustering dynamics for aged $\mathrm{Cu}$-doped $\mathrm{Bi}_{2} \mathrm{Te}_{3}$ crystals. Nat. Commun. 2014, 5. [CrossRef] [PubMed]

12. Zhang, Y.; Jia, X.; Sun, H.; Sun, B.; Liu, B.; Liu, H.; Kong, L.; Ma, H. Suppressing adverse intrinsic conduction of $\mathrm{Bi}_{2} \mathrm{Te}_{3}$ thermoelectric bulks by $\mathrm{Sb}$ and $\mathrm{Cu}$ co-substitutions via HPHT synthesis. RSC Adv. 2016, 6, 7378-7383. [CrossRef]

13. Lim, Y.S.; Song, M.; Lee, S.; An, T.H.; Park, C.; Seo, W.S. Enhanced thermoelectric properties and their controllability in p-type (BiSb) ${ }_{2} \mathrm{Te}_{3}$ compounds through simultaneous adjustment of charge and thermal transports by $\mathrm{Cu}$ incorporation. J. Alloys Compd. 2016, 687, 320-325. [CrossRef] 
14. Zhang, J.; Ming, W.; Huang, Z.; Liu, G.; Kou, X.; Fan, Y.; Wang, K.; Yao, Y. Stability, electronic, and magnetic properties of the magnetically doped topological insulators $\mathrm{Bi}_{2} \mathrm{Se}_{3}, \mathrm{Bi}_{2} \mathrm{Te}_{3}$, and $\mathrm{Sb}_{2} \mathrm{Te}_{3}$. Phys. Rev. B 2013, 88 . [CrossRef]

15. Shen, J.; Hu, L.; Zhu, T.; Zhao, X. The texture related anisotropy of thermoelectric properties in bismuth telluride based polycrystalline alloys. Appl. Phys. Lett. 2011, 99, 124102. [CrossRef]

16. Qiu, P.; Zhang, T.; Qiu, Y.; Shi, X.; Chen, L. Sulfide bornite thermoelectric material: A natural mineral with ultralow thermal conductivity. Energy Environ. Sci. 2014, 7, 4000-4006. [CrossRef]

17. Ioffe, I.F. Semiconductor Thermoelements and Thermoelectric Cooling; Infosearch Ltd.: London, UK, 1957; pp. 24-32.

18. Cheng, N.; Liu, R.; Bai, S.; Shi, X.; Chen, L. Enhanced thermoelectric performance in Cd doped CuInTe2 compounds. J. Appl. Phys. 2014, 115, 163705. [CrossRef]

19. Hu, L.; Zhu, T.; Wang, Y.; Xie, H.; Xu, Z.; Zhao, X. Shifting up the optimum figure of merit of p-type bismuth telluride-based thermoelectric materials for power generation by suppressing intrinsic conduction. NPG Asia Mater. 2014, 6. [CrossRef]

20. Xie, W.; He, J.; Kang, H.; Tang, X.; Zhu, S.; Laver, M.; Wang, S.; Copley, J.R.D.; Brown, C.M.; Zhang, Q.; et al. Identifying the specific nanostructures responsible for the high thermoelectric performance of $(\mathrm{Bi}, \mathrm{Sb})_{2} \mathrm{Te}_{3}$ nanocomposites. Nano Lett. 2010, 10, 3283-3289. [CrossRef] [PubMed]

21. Fan, X.; Yang, J.; Zhu, W.; Bao, S.; Duan, X.; Xiao, C.; Zhang, Q.; Xie, Z. Effect of nominal $\mathrm{Sb}_{2} \mathrm{Te}_{3}$ content on thermoelectric properties of p-type $\left(\mathrm{Bi}_{2} \mathrm{Te}_{3}\right)_{x}\left(\mathrm{Sb}_{2} \mathrm{Te}_{3}\right)_{1-x}$ alloys by MA-HP. J. Phys. D Appl. Phys. 2006, 39, 5069-5073. [CrossRef]

22. Zheng, Y.; Zhang, Q.; Su, X.; Xie, H.; Shu, S.; Chen, T.; Tan, G.; Yan, Y.; Tang, X.; Uher, C.; et al. Mechanically robust BiSbTe alloys with superior thermoelectric performance: A case study of stable hierarchical nanostructured thermoelectric materials. Adv. Energy Mater. 2015, 5. [CrossRef]

23. Xu, Z.; Hu, L.; Ying, P.; Zhao, X.; Zhu, T. Enhanced thermoelectric and mechanical properties of zone melted p-type $(\mathrm{Bi}, \mathrm{Sb})_{2} \mathrm{Te}_{3}$ thermoelectric materials by hot deformation. Acta Mater. 2015, 84, 385-392. [CrossRef]

24. Zevalkink, A.; Toberer, E.S.; Zeier, W.G.; Flage Larsen, E.; Snyder, G.J. Ca3AlSb3: An inexpensive, non-toxic thermoelectric material for waste heat recovery. Energy Environ. Sci. 2011, 4, 510-518. [CrossRef]

25. Li, S. Semiconductor Physical Electronics, 2nd ed.; Springer Science + Business Media: New York, NY, USA, 2006; pp. 217-221.

26. Yazyev, O.V.; Moore, J.E.; Louie, S.G. Spin polarization and transport of surface states in the topological insulators $\mathrm{Bi}_{2} \mathrm{Te}_{3}$ and $\mathrm{Bi}_{2} \mathrm{Se}_{3}$ from first principles. Phys. Rev. Lett. 2010, 105, 266806. [CrossRef] [PubMed]

27. Liu, W.; Chi, H.; Sun, H.; Zhang, Q.; Yin, K.; Tang, X.; Zhang, Q.; Uher, C. Advanced thermoelectrics governed by a single parabolic band: $\mathrm{Mg}_{2} \mathrm{Si}_{0.3} \mathrm{Sn}_{0.7}$, a canonical example. Phys. Chem. Chem. Phys. 2014, 16, 6893-6897. [CrossRef] [PubMed]

28. Yang, F.; Ikeda, T.; Snyder, G.J.; Dames, C. Effective thermal conductivity of polycrystalline materials with randomly oriented superlattice grains. J. Appl. Phys. 2010, 108. [CrossRef]

29. Yan, X.; Poudel, B.; Ma, Y.; Liu, W.; Joshi, G.; Wang, H.; Lan, Y.; Wang, D.; Chen, G.; Ren, Z. Experimental studies on anisotropic thermoelectric properties and structures of n-Type $\mathrm{Bi}_{2} \mathrm{Te}_{2.7} \mathrm{Se}_{0.3}$. Nano Lett. 2010, 10, 3373-3378. [CrossRef] [PubMed]

30. Chiritescu, C.; Mortensen, C.; Cahill, D.G.; Johnson, D.; Zschack, P. Lower limit to the lattice thermal conductivity of nanostructured $\mathrm{Bi}_{2} \mathrm{Te}_{3}$-based materials. J. Appl. Phys. 2009, 106. [CrossRef]

31. Callaway, J. Model for lattice thermal conductivity at low temperatures. Phys. Rev. 1959, 113, $1046-1051$. [CrossRef]

32. Zhu, T.; Fu, C.; Xie, H.; Liu, Y.; Feng, B.; Xie, J.; Zhao, X. Lattice thermal conductivity and spectral phonon scattering in FeVSb-based half-Heusler compounds. EPL 2013, 104. [CrossRef]

33. Blank, V.D.; Buga, S.G.; Kulbachinskii, V.A.; Kytin, V.G.; Medvedev, V.V.; Popov, M.Y.; Stepanov, P.B.; Skok, V.F. Thermoelectric properties of $\mathrm{Bi}_{0.5} \mathrm{Sb}_{1.5} \mathrm{Te}_{3} / \mathrm{C}_{60}$ nanocomposites. Phys. Rev. B 2012, 86. [CrossRef]

34. Slack, G.A.; Galginaitis, S. Thermal conductivity and phonon scattering by magnetic impurities in CdTe. Phys. Rev. 1964, 133, A253-A268. [CrossRef]

(C) 2017 by the authors. Licensee MDPI, Basel, Switzerland. This article is an open access article distributed under the terms and conditions of the Creative Commons Attribution (CC BY) license (http:/ / creativecommons.org/licenses/by/4.0/). 